\title{
José Carlos Mariátegui, Pablo Neruda y Luis Cardoza y Aragón. Tres cartas, dos épocas
}

\section{Eduardo Serrato Córdova}

En el archivo Lya Kostakowsky y Luis Cardoza y Aragón están depositadas tres cartas que se refieren a dos momentos importantes de la vida de Cardoza y Aragón. Las dos primeras, de 1928 y 1929, las remitió hasta Lima, Perú, a José Carlos Mariátegui. La última es una carta que Pablo Neruda le envió a Luis Cardoza cuando el primero salía de Guatemala en 1950 en una visita de cortesía que Neruda hizo al gobierno democrático guatemalteco y Luis Cardoza era embajador de su país en Francia.

La primera carta que Cardoza le escribió a Mariátegui está fechada en 1928 en París. El poeta guatemalteco acababa de ingresar a trabajar en el consulado de su país y estaba a punto de recibir su nombramiento como embajador en Cuba. En esa época, además de la efervescencia de las vanguardias, se vivía un gran activismo político en los círculos de intelectuales latinoamericanos. No sería raro que Cardoza hubiera conocido a Mariátegui por medio de la gente de la Alianza Popular Revolucionaria Americana que estaba exiliada en París. Luis Cardoza, como Miguel Ángel Asturias y otros intelectuales latinoamericanos, se movía en un círculo muy cercano a José Ingenieros, José Vasconcelos, Miguel de Unamuno y Víctor Raúl Haya de la Torre. Incluso junto con estudiantes y un buen grupo de refugiados centroamericanos en París participaron en un mitin, en 1928, en apoyo al gobierno de Plutarco Elías Calles, en un momento en que las relaciones con los Estados Unidos estaban a punto de romperse por la cuestión petrolera. Así que no es de extrañar que Cardoza se sintiera atraído por las ideas sociales y estéticas de José Carlos Mariátegui.

La segunda carta, fechada en 1929, en La Habana, Cuba, hace referencia al protagonismo de uno de los intelectuales que más influyeron en la utopía social de los años treinta en Latinoamérica, Waldo Frank, 
amigo cercano de Alfonso Reyes y de Victoria Ocampo. La carta nos revela la decepción de Luis Cardoza y Aragón cuando escuchó al filósofo en una conferencia dictada en La Habana. Frank más que un filósofo era recibido en los países que visitaba como un profeta. Incluso durante los años treinta, Frank visitó la ciudad de México. En esa ocasión Cardoza se mantuvo al margen de Frank y su discurso mesiánico.

La influencia de Mariátegui en el pensamiento de Cardoza es un tema por estudiar, sólo quiero señalar que en la introducción a Siete ensayos de interpretación de la realidad peruana (1928), Mariátegui escribió:

[...] He hecho en Europa mi mejor aprendizaje. Y creo que no hay salvación para Indo-América sin la ciencia y el pensamiento europeos u occidentales. Sarmiento, que es todavía uno de los creadores de la argentinidad, fue en su época un europeizante. No encontró mejor modo de ser argentino (14).

Luis Cardoza planteó durante el cardenismo la misma idea universalista de la cultura, por lo que recibió duras críticas de parte de los nacionalistas a ultranza, particularmente de los muralistas.

Para quien estudie la vida y la obra de Cardoza estas dos cartas a Mariátegui nos enseñan que Cardoza estaba muy al tanto de lo que publicaba Mariátegui, y que fue un fiel lector del político peruano. No es casual que uno de los libros que más influyeron en la obra ensayística del guatemalteco fuera Siete ensayos de interpretación de la realidad peruana (1928), que sin duda fue el modelo que siguió para escribir Guatemala: las líneas de su mano (1954). El ensayo que Cardoza le envía a Mariátegui sobre Waldo Frank no alcanzó a publicarse, pues a los pocos meses falleció el intelectual peruano.

Luis Cardoza y Pablo Neruda se conocieron en la ciudad de México, en 1943. En ésa época Cardoza era periodista cultural de El Nacional. En El río...(1986) el guatemalteco evoca la querella que ocurrió en ese año entre Neruda, Octavio Paz y José Luis Martínez. La puya inicial la clavó Neruda cuando declaró que en su opinión lo mejor de México eran los agrónomos y los pintores, pues la novela, la poesía y sobre todo "el ensayo ha sido maleado por una generación anémica" (1986: 689). Paz y Martínez salieron a la defensa de su generación y el primero fue claro y certero en su respuesta: "Lo que nos separa de su persona (Neruda) no son las convicciones políticas sino, simplemente, 
la vanidad... y el sueldo. La vanidad que lo obliga a aceptar cada seis meses banquetes y homenajes[...]" (689).

Pablo Neruda fue despedido el 27 de agosto de 1943 en una cena homenaje que se celebró en el Frontón México, que hizo época. Asistió la plana mayor del cardenismo, Cardoza incluido. Por supuesto, faltaron Octavio Paz, José Luis Martínez, Diego Rivera que "estaba de trotskista; Alfaro Siqueiros vivía en Chile, por intentar asesinar a Trotski en 1940" (1986: 690).

La carta que Pablo Neruda le envió a Cardoza nos comunica el optimismo por las nuevas condiciones políticas y culturales guatemaltecas. Es una carta escrita en 1950, cuando Guatemala pasaba por su brevísima primavera democrática. Cardoza en 1944, cuando fue derrotada la junta militar, salió de México rumbo a su patria, como lo narra en las primeras páginas de Guatemala: las líneas de su mano. Pablo Neruda ignoraba que Cardoza estaba siendo duramente atacado y boicoteado desde el gobierno mismo por funcionarios menores que obstaculizaban sus propuestas diplomáticas y que habían visto con muy malos ojos el libro de viajes de Cardoza, Retorno al futuro (1947), que era una defensa y encomio de la sociedad soviética. ${ }^{1}$

Carlos Navarrete hace una evocación del regreso de Cardoza a Guatemala en 1950, antes de que la cuestión se tornara insostenible y después de la visita de Pablo Neruda a Guatemala:

Las puertas del departamento de Luis siempre estuvieron abiertas para los miembros del Grupo Saker-Ti, entre los más frecuentes Humberto Alvarado, José Enrique Torres, Jacobo Rodríguez Padilla, Manolo Herrarte y José Arévalo Guerra. Con los primeros tres me colé para recibirlo al aeropuerto en 1950, al terminar su gestión diplomática en Francia. Mientras corrían los trámites y luego el taxi, Luis fue directo a las pre-

\footnotetext{
${ }^{1}$ Navarrete (2002) explica los “pecados” de Cardoza: "La derecha acusaba a Luis de ser ideólogo del comunismo, no perdonaba su voto obrerista en la Constituyente de 1945 y su aceptada propuesta para que el Día de los Trabajadores, el $1^{\circ}$ de mayo, se declarara fiesta oficial. El suplemento dominical del Diario de la Mañana publicó 'El Primero de Mayo en Moscú', capítulo adelantado de su libro sobre la Unión Soviética, otra razón para quedar señalado. De él partió la iniciativa para el rompimiento de relaciones con Franco y el establecimiento de las mismas con la URSS. La cerrada sociedad guatemalteca no podía tolerar la presencia de alguien que hubiera vivido en un país comunista y, peor aún, que escribiera positivamente de sus vivencias" (20).
} 
guntas y comentarios. Iba en el asiento delantero y volteaba ligeramente al hablar. Mirada de águila y perfil de lobo ("Lobo para mis amigos, para usted Luis Cardoza y Aragón que a los diecinueve años había escrito su primer libro", le espetó a un periodista que lo llamó por su apodo). "Vi a Arturo (Martínez) en París. Trabajaba bien, metido en exposiciones y museos. De Cantel a París con escala en New York ¡quién lo creyera! Traigo una carpeta de litografías de artistas latinoamericanos residentes en Francia: Chávez Morado, Wilfredo Lam...” (15).

Pablo Neruda menciona también al grupo Saker-Ti integrado por Carlos Navarrete, José Luis Balcárcel, Raúl Leyva, Augusto Monterroso, Melvin René Barahona, Abelardo Rodas, Humberto Alvarado, José María López Valdizón y Óscar Arturo Palencia. Antes de salir al exilio voluntario en Europa y luego en México, Cardoza participó con el grupo en la fundación de revistas, en el montaje de exposiciones, en la organización de recitales y conferencias y, en pocas palabras, en la creación de un movimiento intelectual a la altura de la renovación política que experimentaba Guatemala. 
7 rue de Belzunce

París. 15 de marzo de 1928

\section{Carlos Mariátegui. ${ }^{2}$ \\ Lima.}

Le envío en pruebas, con todo afecto, este ensayo — ditirámbico- sobre Carlos Mérida, ${ }^{3}$ arte americano, en general, así como algunas reproducciones de Mérida y otras de Agustín Lazo, uno de los mejores pintores jóvenes de México como Ud. podrá juzgar, aunque someramente, por las fotografías que aquí van. No sé si Rabínez le envió ya unas cuartillas sobre Gómez Carrillo. ${ }^{4}$ Esta vez decidí hacerlo yo directamente.

\footnotetext{
${ }^{2}$ José Carlos Mariátegui (1895-1930). Periodista y activista político. En los años veinte tuvo una activa participación política en Perú y en Italia, en donde recibió su formación política. En 1928 reapareció la revista Amauta, que había sido censurada por el gobierno. En abril de ese año se dio la ruptura entre Mariátegui y Haya de la Torre y su consecuente salida del APRA. El 8 de octubre de 1928 se constituyó formalmente el Partido Socialista con Mariátegui como secretario general. En noviembre apareció el volumen Siete ensayos de interpretación de la realidad peruana. En mayo de 1929, publicó en la revista Mundial su novela corta La novela y la vida. En septiembre de 1929, la casa de Mariátegui fue allanada, esta vez debido a un supuesto "complot judío". En marzo de 1930, Mariátegui fue internado de emergencia en la Clínica Villarán. Murió el 16 de abril.

${ }^{3}$ Carlos Mérida (1891-1984). Pintor guatemalteco. Muchas fueron las páginas que Cardoza le dedicó a la pintura de Carlos Mérida. En su importante libro La nube y el reloj (1940), Cardoza y Aragón considera que Mérida fue el artista que abrió el camino plástico de la primitivista latinoamericana. El trabajo sobre Mérida se publicó como "Ensayo sobre el arte del trópico", Amauta, núm. 14, abril de 1928: 12, 31-36.

${ }^{4}$ Enrique Gómez Carrillo (1873-1927). Fue el escritor modernista que más influyó en el imaginario literario del joven Luis Cardoza, principalmente su autobiografía, El despertar del alma (1918). Curiosamente, el itinerario que Gómez Carrillo realizó como periodista y diplomático es casi el mismo que Luis Cardoza y Aragón realizó a
} 
La amistad vigilante de Rabínez, me informó de la suspensión de Amauta ${ }^{5}$ de su encarcelamiento, de los expulsados, etc. y de la nueva reaparición de la revista que tanto desearía ver siempre. Sigo el esfuerzo de Ud. con mucho interés y créame que le estimo sinceramente.

$\mathrm{Su}$ afectuoso servidor.

L. Cardoza y Aragón.

La Habana,

Navidad de 1929

\section{Estimado Mariátegui:}

Aquí van estas cuartillas sobre Waldo Frank. ${ }^{6}$ Las formé. Como Ud. verá, para un diario de mi país, Guatemala; pero tal vez tengan algún

lo largo de su vida. En cierta manera, la vida literaria de Gómez Carrillo fue la premonición de la de Cardoza.

${ }^{5}$ Amauta, revista literaria peruana fundada en Lima por José Carlos Mariátegui, a la que imprimió su personal carácter, y que fue la más importante e influyente en Perú durante la década de 1920. Se publicaron, desde 1926 hasta 1930, fecha de la muerte de su fundador, 32 números. Amauta es un nombre quechua que significa 'sabio', 'consejero', y eso pretendió ser Mariátegui en la redacción y consiguió que fuera la revista para muchos escritores que llegaron después. A pesar de la ideología marxista leninista de Mariátegui no pretendió que la publicación fuera sólo un órgano político y partidista, sino que vinculó los planteamientos indigenistas y sociales con los estéticos y literarios de las vanguardias europeas y peruanas, así como con los de escritores anteriores, en especial Manuel González Prada, por lo que fue la mejor manifestación del vanguardismo nacional. Entre los muchos escritores que colaboraron en sus páginas se cuentan César Vallejo, Xavier Abril, Alberto Hidalgo, César Falcón y Waldo Frank.

${ }^{6}$ Waldo Frank (1889-1967) fue uno de los escritores del nuevo socialismo utópico que más influyó en las ideas de los años cuarenta en América Latina. Fue amigo íntimo de Alfonso Reyes y de la mecenas argentina Victoria Ocampo. Es interesante cómo Cardoza muestra su desencanto al escuchar a Frank, quien estaba en vías de convertirse en el profeta del nuevo cambio latinoamericano. Visitó México en 1936, durante el cardenismo. El libro América hispana es la suma de su pensamiento filosófico en donde plantea que la riqueza cultural mesoamericana debe mezclarse con los avances de la tecnología moderna para acabar con la pobreza de las naciones hispánicas. Fue, también, colaborador de Cuadernos Americanos, junto con Luis Cardoza y Aragón, Alfonso Reyes y Leopoldo Zea. Curiosamente, a pesar de su exitosa gira de 
interés y pueda justificarse su publicación al menos en fragmentos. Tanto mejor si en Amauta. De París, un amigo que dejé al cuidado de mi correspondencia me dice de [sic] haberme enviado "Siete ensayos en busca de la Realidad Peruana”, que imagino que Ud. tuvo la delicada atención de remitírmelo. Pero... no llegó nunca el libro suyo, y quiero leerlo. Le agradeceré muchísimo su envío.

He marcado con una cruz roja al margen, desde dónde se podría publicar el escrito sobre Frank. Los párrafos anteriores a la seña, se refieren en absoluto a Guatemala.

Yo no sé qué impresión le dio Frank a Ud. personalmente. "1929" la revista de nuestros amigos cubanos (un tanto tímida, conservadora) ${ }^{7}$ le dio una comida y de sobre-mesa pude armar discursos, provocar a Frank en la intimidad a que nos manifestara su criterio sobre varios puntos. En las conferencias, por dirigirse a un público grande, vario, era natural cierto tono. Ya entre gente joven, debió habernos mostrado mejor su mente. Y sobre todo porque sabía nuestra simpatía y cordialidad hacia él. En fin, quiero decirle resumiendo, que no nos dijo nada original, audaz, o bien inteligente. Fueron las mismas conferencias que Uds. oyeron. ¿No le parece de un tono, a pesar de todo, en la mediana - decente- pero en la mediana categoría?

Aquí está este escrito, Mariátegui, haga con él lo que le plazca.

Sepa que le estima y quiere hace tiempo su amigo afectuoso.

Buen y fecundo 1930 .

Luis Cardoza y Aragón

Edificio Montes

Línea y D.

Vedado (La Habana)

Cuba

lecturas por Latinoamérica en 1942, de la publicación de su diario South American Journey (1943) y de las crónicas de Birth of a World: Simon Bolivar in Terms of His Peoples (1951), Frank prefirió regresar a escribir novelas. En los últimos años de su vida su popularidad se extinguió al grado de que no encontró editor para sus dos últimas novelas. Murió en 1967 olvidado por sus críticos y lectores.

7 Recordemos que durante la breve estancia de Cardoza en Cuba, mayo de 1929abril de 1930, entabló amistad con Juan Marinello, Jorge Mañach y los demás redactores de la revista que cambió su nombre al de 1930. En El río... se queja también de la solemnidad de los editores (1986: 326-327). 
Junio 1950

Querido Luis, vuelvo de tu país que adoro. Hablé de ti en prensa y privado. Hablé también con J.J. Pero no te adelanto porque llegamos a esa a fines de Julio (solo a Alice y P. E. puedes decirles). Para ti llegamos a Cannes, el 10 de Julio. Barco "Argentina”. Consulich, Homelines, agentes Cook y Jones.

Ojalá nos dieras el placer inmenso de venir a esperarnos con Lya, y con Paul y su mujer. Vengo lleno de olor a caoba (el aroma de Guatemala), de $S a k e r t i^{8}$ y de Amanecer. Llevo tu prólogo para que lo leamos juntos.

Abrazos, Pablo.

Búscanos $[$ sic $]$ apartamento?

BiBLIOGRAFÍA

Cardoza y Aragón, Luis. Guatemala: las líneas de su mano. México: Fondo de Cultura Económica, 1978.

—. El río. Novela de caballerías. México: Fondo de Cultura Económica, 1986.

- La nube y el reloj. Pintura mexicana contemporánea. 2a ed. Presentación de Rita Eder. Estudio Preliminar de Renato González Mello. México: Universidad Nacional Autónoma de México/Instituto de Investigaciones Estéticas, 2003.

Mariátegui, José Carlos. Siete ensayos de interpretación de la realidad peruana. México: Era, 1979.

Navarrete, Carlos. Luis Cardoza y Aragón y el grupo Saker-ti. Guatemala: Universidad de San Carlos, 2002.

${ }^{8}$ Como he apuntado en la introducción, el grupo Saker-Ti, amanecer en mayaquiché, estaba integrado por jóvenes comunistas que se habían propuesto modernizar y revolucionar la cultura guatemalteca. 